\title{
Preparation and Performance Assessment of Asphalt Emulsion Modified by the Fabricated SBS Latex
}

\author{
Rui He $\mathbb{D}^{1},{ }^{1,2}$ Yingping Liang, ${ }^{1}$ Lining Gao ${ }^{D},{ }^{1}$ Huaxin Chen, ${ }^{1}$ Ben Yang, ${ }^{1}$ Fengjun Guo, ${ }^{3}$ \\ and Jiuguang Geng ${ }^{1}$ \\ ${ }^{1}$ School of Materials Science and Engineering, Chang'an University, Xi'an 710061, China \\ ${ }^{2}$ Shanxi Transportation Technology Research \& Development Co., Ltd., Taiyuan 030032, China \\ ${ }^{3}$ Shanxi Province Expressway Group Limited Liability Company, Taiyuan 030006, China \\ Correspondence should be addressed to Lining Gao; lngao@chd.edu.cn
}

Received 29 October 2020; Accepted 26 November 2020; Published 3 December 2020

Academic Editor: Shaopeng Wu

Copyright (C) 2020 Rui He et al. This is an open access article distributed under the Creative Commons Attribution License, which permits unrestricted use, distribution, and reproduction in any medium, provided the original work is properly cited.

Polymer modified asphalt emulsion (PMAE) has recently been proven to be one of the most effective methods to overcome the common distress of asphalt surface treatments, such as abrasion, rutting, ravelling, and poor durability. Because of the limited research studies about the preparation of PMAE using SBS latex, a new method to prepare SBS latex was developed and the feasibility of using it in preparing SBS latex modified asphalt emulsion (SBS-LMAE) was verified in this study. The optimized swelling parameters for linear SBS solutions were swelling $24 \mathrm{~h}$ at the temperature of $50^{\circ} \mathrm{C}$ with the toluene/SBS (T/S) mass ratios of $2.5: 1$ to $2.0: 1$ which was determined according to the analysis of viscosity and Tyndall effect. After that, the SBS latex with favorable dispersivity and stability was successfully fabricated with the T/S ratio of $2.0: 1$. At last, the well-specified SBS-LMAE was prepared using the fabricated latex and tested for its conventional performances and microstructure. The results show that the SBS-LMAE samples all meet the main requirements of PMAE for microsurfacing and possess appropriate uniformity and stability.

\section{Introduction}

Compared with the conventional hot-mix asphalt, asphalt emulsions (AEs) are more energy efficient, environmentally friendly, and cost-effective [1]. Therefore, it has been widely used in different pavement applications, such as tack coat, chip-sealing, microsurfacing, and cold asphalt mixtures. During the past decades, $\mathrm{AE}$ is becoming a viable alternative to hot-mix asphalt, which makes asphalt pavements more economic, less polluting, lower energy consumption, and longer construction season [2,3]. However, confronted with the severe distress and deteriorates of pavement that caused by the recent significant increase in traffic volume and tire pressure, higher requirements of $\mathrm{AE}$ have been raised by modern engineering in aspects like sufficient strength and thermal stability at high temperature, necessary flexibility and plasticity at low temperature, adequate antiaging ability during service, and high adhesion strength to aggregates and surfaces of structures [4-6]. This object has been achieved upon using polymer modified asphalt emulsion (PMAE) nowadays, which possesses more advantages in terms of high- and low- temperature performances, fatigue resistance, and water stability when compared with conventional $\mathrm{AE}$.

PMAE is a type of AE that is modified with polymer emulsion (latex) or a product made by emulsifying polymer modified asphalt [6]. It maintains the advantages of both modified asphalt and AE. At present, the most widely used polymers for PMAE are styrene-butadiene rubber (SBR) latex, natural rubber (NR) latex, styrene-butadiene styrene (SBS), and waterborne epoxy resin (WER) [4, 7]. Among them, SBS has been proven to be the most effective polymer to improve the physical and mechanical properties and rheological behaviors of asphalt due to its cross-linked elastomer network structure $[8,9]$. In addition, now it has become the most widely used polymer for modifying asphalt. However, the difficulty of emulsification of modified asphalt increases sharply and the storage stability usually 
cannot meet specifications with the increasing SBS concentration in matrix asphalt, especially when SBS concentration is over $4 \%$ [10]. The aqueous phase form of SBR and NR latexes enables them to be blended with $\mathrm{AE}$ at ambient temperature and even without high shear, leading them to be frequently used to modify AE. Engineering practices show that addition of SBR to AE causes significant improvements in low-temperature ductility, viscosity, elastic recovery, and cohesive properties of the pavement, but the high-temperature performance is slightly modified $[6,11]$. NR modification can increase the stiffness and reduce the temperature susceptibility of asphalt residues, but the low elastic recovery properties were unacceptable [4]. Even though the AE modified by WER has excellent high-temperature performance, the low-temperature ductility is slightly improved and its cost is high [12]. Therefore, it is necessary to continue exploring the potential of applying SBS polymer to modified AE. However, the preparation process of PMAE containing the SBS modifier is difficult, and the industrial production has a great limitation [13].

In view of abovementioned problems, researchers have carried out a lot of research studies on AE modified by SBS. Cai et al. [10] proposed a method of fabricating SBS latex and preparing of SBS latex modified asphalt emulsion (SBSLMAE) by postadding the latex into AE. This research demonstrated the feasibility and advantage of adopting SBS latex to prepare PMAE. Wang et al. [13] adopted self-made emulsifier to prepare PMAE by emulsifying SBS modified asphalt with the content of SBS at 3.0\%-3.5\% by mass. The results showed that the $\mathrm{AE}$ with good storage stability could be obtained by adjusting the emulsification conditions according to the relationship between physical properties and storage stability. However, the content of SBS is still low, and the performance improvement is limited. Abd ElRahman et al. [6] modified AE using a mixture of commercial SBS latex, epoxy resin, and PVA. It was found that the prepared PMAE possessed the highest viscosity value, and it was qualified to be used for pavement in different applications.

Previous studies indicate that further attention still needs to be paid on the optimization of PMAE by SBS and to promote the application of this technology in pavement engineering. Therefore, this research endeavored to develop a new method to prepare SBS latex and verify the feasibility of using it in preparing SBS-LMAE. The research process was divided into two steps. At the first step, the fabrication process and formulation of SBS latex were discussed and the performance was evaluated. At the second step, the wellspecified SBS-LMAE was prepared by using the fabricated SBS latex as a modifier, and its performance was evaluated by the conventional test and morphology analysis.

\section{Materials and Methods}

2.1. Materials. A 90 penetration grade asphalt produced by SK Company of South Korea was used to prepare samples of PMAE, and the basic properties are shown in Table 1. The line structure SBS (1301) with a block rate of 30/70 was from
TABLE 1: Basic properties of the matrix asphalt.

\begin{tabular}{lcc}
\hline Technical index & Test value & Method \\
\hline Penetration $\left(25^{\circ} \mathrm{C}\right) / 0.1 \mathrm{~mm}$ & 89 & JTG E20-2011 T0604 \\
Ductility $\left(15^{\circ} \mathrm{C}\right) \mathrm{cm}$ & $>150$ & JTG E20-2011 T0605 \\
Softening point ${ }^{\circ} \mathrm{C}$ & 48.5 & JTG E20-2011 T0606 \\
\hline
\end{tabular}

Baling Petrochemical Company (Yueyang, China). The chemical reagents used in the research included cetyl trimethyl ammonium bromide (CTAB, cationic emulsifier, $\mathrm{AR}$ ), nonyl phenol polyoxyethylene ether (OP-10, nonionic emulsifier, AR), anhydrous calcium chloride (inorganic stabilizer, AR), polyvinyl alcohol (organic stabilizer, AR), toluene (solvent, $\mathrm{AR}$ ), hydrochloric acid ( $\mathrm{pH}$ adjusting agent, AR), and cationic slow-cracking fast-setting emulsifier (CSFE, Shandong Banghua Oil Chemical Company, China).

\subsection{Sample Fabrication}

2.2.1. Swelling of SBS in Toluene. SBS is a styrene-butadienestyrene triblock polymer, and its molecules are composed of PS segment and PB segment. Most solvents only have good solubility in a certain block in SBS, such as cyclohexane and hexane act as selective solvents for PB segments, while ethyl acetate and butanone are selective solvents for PS segment. All things considered, the toluene with good solubility for both PS and PB segments was selected as the single solvent for swelling SBS. SBS swelling process was described as follows: at room temperature, the SBS toluene solution was prepared in the wide mouth bottle with the mass ratio (toluene:SBS, T/S) of $3.5: 1,3.0: 1,2.5: 1,2.0: 1$, and $1.5: 1$, sealed and preserved (preventing toluene volatilization), and swelled for $24 \mathrm{~h}$. During this period, the swelling status is continuously observed, and the swelling of the SBS in toluene was observed by the Tyndall effect. The called Tyndall effect is an optical phenomenon that when a light beam passes through a colloid, the suspended particles in the path will scatter the light, enabling a beam of light to become visible $[14,15]$. This effect makes it possible the qualitative comparison of dispersion stability for SBS solution due to its colloidal nature.

2.2.2. Preparation of SBS Latex. The optimal latex formula was obtained by using four-factor four-level orthogonal experimental design. SBS latex preparation process included the following: (1) the swollen SBS solution was placed in a programmable-controller bath and kept at $50 \pm 2^{\circ} \mathrm{C}$ for $30 \mathrm{~min}$; (2) the cationic emulsifier, nonionic emulsifier, inorganic stabilizer, and organic stabilizer were formulated into soap liquid according to the formula, and the $\mathrm{pH}$ regulator was added to adjust the $\mathrm{pH}$ value of soap liquid to $2-3$; (3) the soap liquid was heated to $65-70^{\circ} \mathrm{C}$ and then poured into the colloid mill (MD-1, Jiaxing Mide Machinery Co., Ltd., China) which was preheated to $65-70^{\circ} \mathrm{C}$; (4) the soap liquid was stirred in the colloidal mill for $3 \mathrm{~min}$ with a stirring speed at $3000 \mathrm{rpm}$; (5) the SBS solution was added 
into the colloid mill and then stirred for 3 min. Finally, the fabricated SBS latex was placed in a container and sealed.

2.2.3. Distillation and Concentration of SBS Latex. In order to increase the solid content of the latex and reduce the negative effect of toluene on the subsequent performance of SBS-LMAE, the SBS latex needs to be concentrated by distillation. Distillation processing was carried out by atmospheric distillation at a temperature of $80^{\circ} \mathrm{C}$. The distillation completion was judged by the evaporation amount of $30 \%, 30 \%$, and $25 \%$ for the system of $\mathrm{T} / \mathrm{S}=2.5: 1,2.0: 1$, and $1.5: 1$, respectively. The fabricated SBS latex sample is shown in Figure 1.

2.2.4. Preparation of SBS-LMAE. In general, three methods are usually adopted to prepare PMAE: the preadding method, simultaneous-adding method, and the postadding method [7, 16]. For the postadding or biphase emulsion method, the polymer is added to the prepared $\mathrm{AE}$ via the form of latex either in the plant or on-site at ambient temperature. Given these points, this method can not only reduce the energy consumption of heating asphalt but also avoid the dependence on the high-speed shearing machine, substantially reducing the product cost. Therefore, the postadding method was used to prepare SBS-LMAE in this study.

The specific preparation process was as follows: (1) the cationic slow-cracking fast-setting emulsifier, anhydrous calcium chloride, polyvinyl alcohol, and distilled water were formulated into soap liquid according to the dosage of the formula; (2) the soap liquid was stirred and kept constant at the temperature range of $65-70^{\circ} \mathrm{C}$ with the $\mathrm{pH}$ value being adjusted to 2-3; (3) the soap liquid was then poured into the colloid mill and sheared for $3 \mathrm{~min}$; (4) the matrix asphalt, which was preheat to $140 \pm 2^{\circ} \mathrm{C}$, was slowly added to the colloid mill, which was preheated to $65-70^{\circ} \mathrm{C}$, and stirred for 3 min with a stirring speed at $3000 \mathrm{rpm}$; (5) finally, the selfmade SBS latex was added to the asphalt emulsion at room temperature, and the modified emulsification was completed after mechanical stirring for $10 \mathrm{~min}$. The preparation flowchart is shown in Figure 2.

2.3. Test Program. To fulfil the objective of this research work, the test program was mainly divided into three parts: the performance test of swollen SBS, SBS latex and concentrated SBS latex, and SBS-LMAE. Besides, the morphology observation was conducted for both SBS latex and SBS-LMAE.

2.3.1. Performance Test of Swollen SBS. At first, the rheological characteristics of swollen SBS were tested by using the viscometer. The equipment conditions included a Brookfield viscometer (DV-II + Pro, Brookfield), the chosen rotor was $21 \#$, the loading amount was $8.0 \mathrm{~mL}$, and the temperature was $20^{\circ} \mathrm{C}$. The optimum swelling temperature, swelling time, and $\mathrm{T} / \mathrm{S}$ ratio were determined by testing the viscosity. Then, the swelling status and dispersion stability were assessed through visual observation and Tyndall effect as a function of time.

2.3.2. Performance Test of SBS Latex and Concentrated SBS Latex. According to the Chinese standards GB/T 11175-2002, SH/T 1152-2014, and SH/T 1154-2011 [17-19], the main performance indexes of SBS latex and SBS concentrated latex are tested: solid content, viscosity, $\mathrm{pH}$ value, particle size and Zeta potential of latex (Zetasizer Nano ZS, Malvern), and mechanical stability.

2.3.3. Performance Test of SBS-LMAE. The modified AE was prepared using cationic slow-cracking fast-setting emulsifier and line SBS latex as a modifier. The storage stability of the emulsion and the penetration, softening point, and ductility of the evaporation residue were tested according to the Chinese standard JTG E20-2011 [20].

2.3.4. Morphology Observation. To further study on the dispersion and stability characteristics, the microstructures of SBS latex and SBS-LMAE were observed by fluorescence microscopy (UG-1, Corning). The samples were viewed under the microscope at a magnification of 400 .

\section{Results and Discussion}

\subsection{Performance Assessment of Swollen SBS}

3.1.1. Effect of Concentration on Viscosity. The SBS solution with a swelling temperature of $50^{\circ} \mathrm{C}$ and a swelling time of $1 \mathrm{~d}$ was used to determine the viscosity of different SBS concentrations $(22.22 \%, 25.00 \%, 28.57 \%, 33.33 \%$, and $40.00 \%)$ in toluene which corresponded to the T/S ratio of $3.5: 1,3.0: 1,2.5: 1,2.0: 1$, and $1.5: 1$, respectively. The results are shown in Figure 3.

It is clear that the viscosity of SBS solutions increases significantly with the rising concentration of SBS, especially when the SBS concentration is larger than $33.33 \%$. It can be explained that with increasing SBS content, the winding between the swollen molecular chains of SBS becomes more serious, forming continuous polymer network in the solution. Therefore, the viscosity of the solution is improved sharply. Considering the difficulty caused by the excessive viscosity of SBS in the preparation of SBS latex as well as the negative effect on the performance of $\mathrm{AE}$ brought by superfluous toluene [21], the following research was mainly conducted on the T/S ratio of $2.0: 1$.

3.1.2. Effect of Temperature on Viscosity of Swollen SBS. The effect of temperature on viscosity of swollen SBS was investigated using the SBS solution with the T/S ratio of $2.0: 1$. The results are shown in Figure 4.

From Figure 4, it is evident that as the temperature increases, the viscosity of SBS solutions shows a tendency to decrease first and then rise. This phenomenon can be explained from two aspects. On the one hand, the thermal movement of the molecular chain is intensified and the 


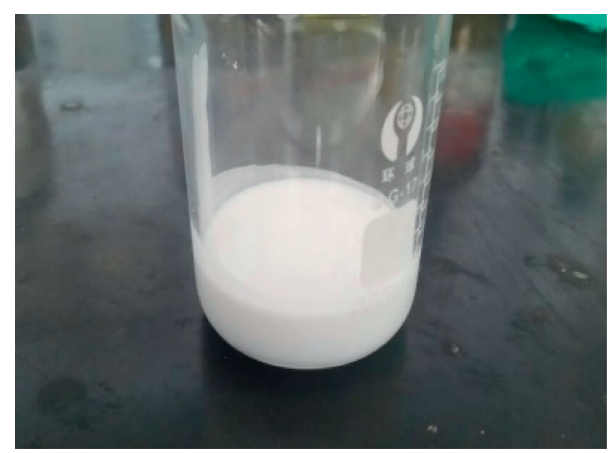

(a)

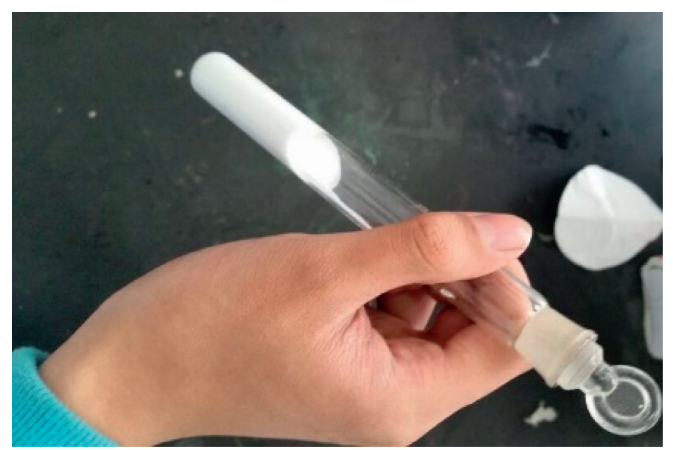

(b)

Figure 1: The fabricated SBS latex.

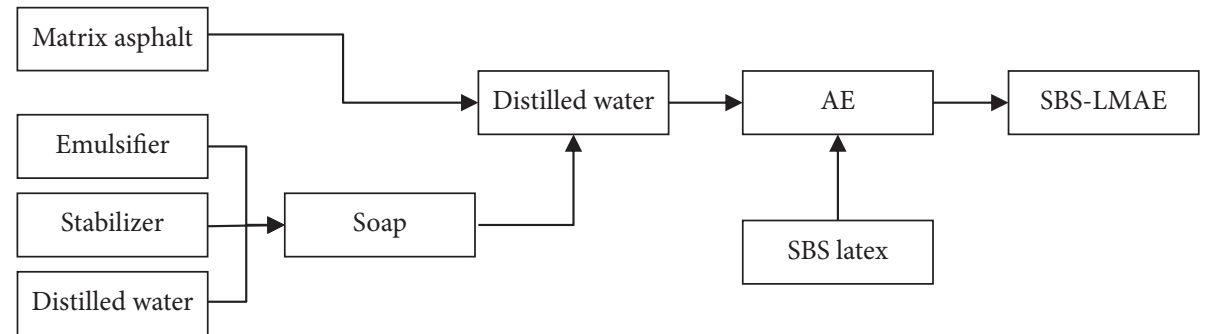

Figure 2: Preparation flowchart of SBS-LMAE.

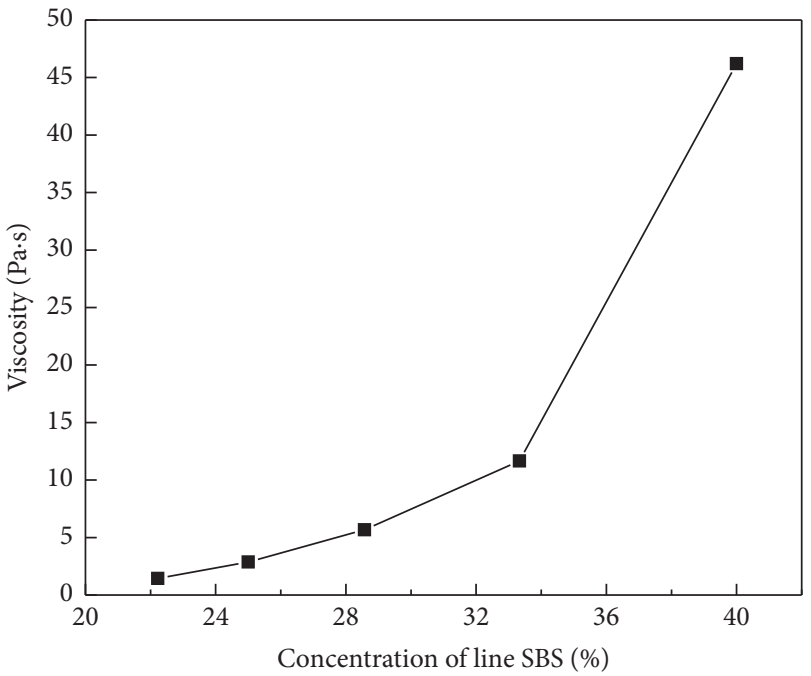

FIGURE 3: Influence of line SBS concentrations on the viscosity of SBS solutions.

content of the solvent adsorbed on the molecular chain is increased with the rise of temperature, leading to the decline of viscosity. On the other hand, the full swelling of the SBS molecular chain at high temperature leads to the formation of polymer network, which becomes dominant when the temperature is over $50^{\circ} \mathrm{C}$ and promotes the viscosity rapidly. Therefore, when the temperature is around $50^{\circ} \mathrm{C}$, the viscosity comes to the minimum. Consequently, $50^{\circ} \mathrm{C}$ is taken as the optimum swelling temperature for the following research.

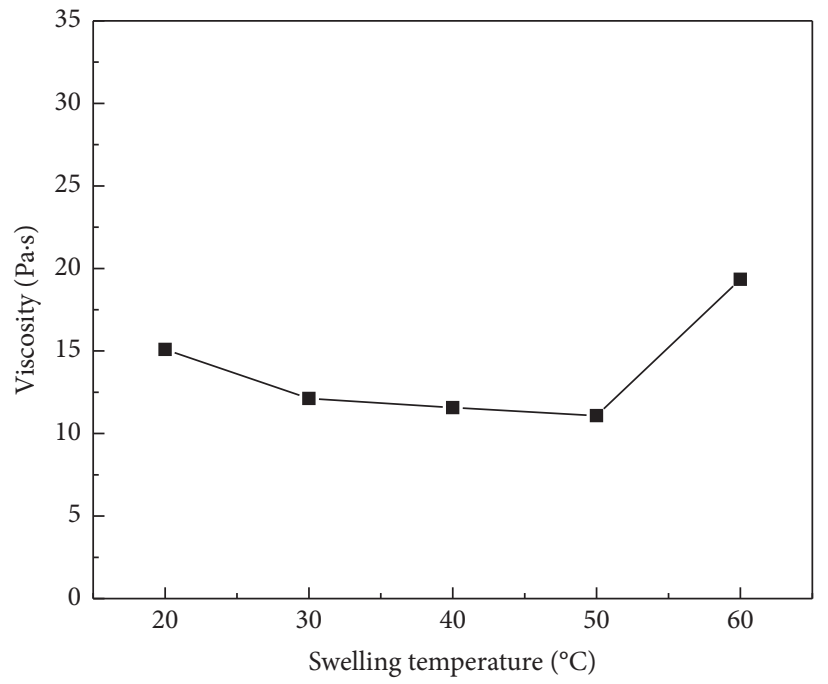

FIgURE 4: Influence of temperature on the viscosity of SBS solutions.

3.1.3. Effect of Time on Swollen SBS. To determine the suitable swelling time, the viscosity of SBS solutions prepared with the swelling temperature of $50^{\circ} \mathrm{C}, \mathrm{T} / \mathrm{S}$ ratio of $2.0: 1$, and different swelling times ( $1 \mathrm{~h}, 2 \mathrm{~h}, 4 \mathrm{~h}, 6 \mathrm{~h}, 12 \mathrm{~h}$, and $24 \mathrm{~h}$ ) was tested, as shown in Figure 5.

It can be seen from Figure 5 that the viscosity almost increases linearly with the swelling time when the swelling time is less than $12 \mathrm{~h}$. Then, the viscosity comes to a plateau and increases slightly after $24 \mathrm{~h}$ swelling. It can be explained that at the initial stage of swelling, SBS is still in the form of 


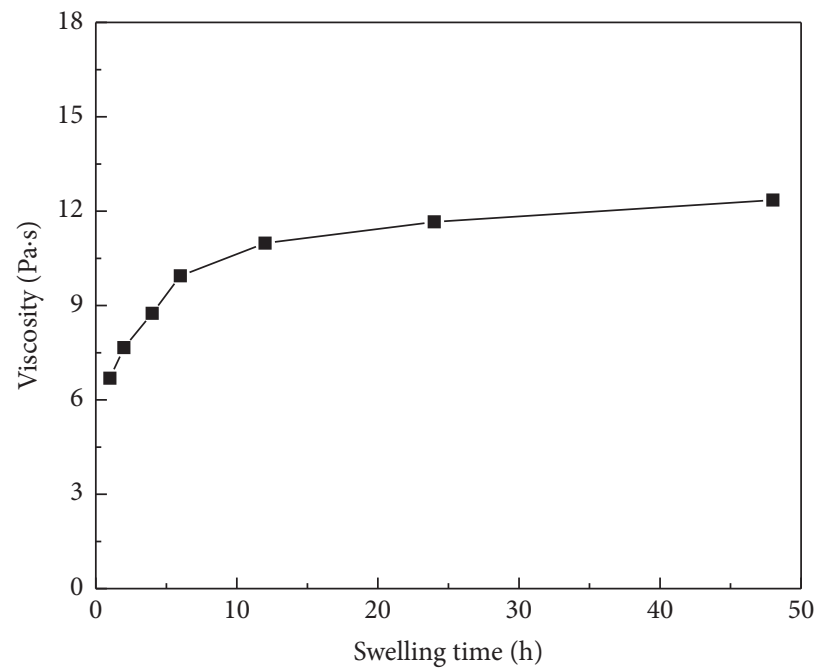

FIgURE 5: Influence of swelling time on the viscosity of SBS solutions.

solid particle, and its molecular chain has not been extended yet, so the viscosity is small. As the swelling time increases, the molecular chain extends and entangles with each other, causing the significant improvement of viscosity. After that, the network structure formed by entangled molecular chains is fulfilled, resulting in a gradual stabilization of viscosity, which also indicates that the SBS swelling is basically complete. So, the swelling time of SBS is obtained to be $24 \mathrm{~h}$.

3.1.4. Swelling Effect of SBS Solution. The results of visualization and comparisons for the Tyndall effect of SBS solutions with the T/S ratios of $2.5: 1,2.0: 1$, and $1.5: 1$ over time are summarized in Figure 6.

It is clear in Figure 6 that light scattering can be observed when the SBS is swollen for $1 \mathrm{~h}$, while the obvious Tyndall effect happens when the swelling time reaches $6 \mathrm{~h}$ and $24 \mathrm{~h}$, respectively. This phenomenon indicates that the droplet size at $1 \mathrm{~h}$ is bigger than the wavelength of light while the droplet size at $6 \mathrm{~h}$ or $24 \mathrm{~h}$ is somewhat below or near the wavelength, which is also in accordance with the discussion in Section 3.1.3. It could be explained that the SBS was not dispersed at the molecular level into the toluene at the initial stage of swelling. So, the light was scattered by the macroparticles of SBS. As the extension of swelling time, SBS was solubilized and the molecules were diffused in the continuous phase. Therefore, the occurrence of the Tyndall effect in our study implies that the colloidal solution of SBS with good dispersion stability is accomplished. In addition, relatively speaking, the T/S ratios of $2.5: 1$ and $2.0: 1$ for SBS solution have more stable dispersion than $1.5: 1$.

\subsection{Performance Assessment of SBS Latex}

3.2.1. Orthogonal Experiment Design of SBS Latex. According to former research, the material composition of SBS latex includes SBS solution, distilled water, stabilizer, and emulsifier [21]. Specifically, the SBS solution used here was fabricated with a T/S ratio of $2.0: 1$, the stabilizer included inorganic stabilizer and organic stabilizer, and the emulsifier was a mix of cationic emulsifier $C T A B$ and nonionic emulsifier OP-10 at a mass ratio of $3: 1$. Therefore, the orthogonal table with four factors and four levels was chosen to select the optimal material formulation of SBS latex, as reported in Table 2.

Three technical indexes were adopted to assess the performance of SBS latex: viscosity, mechanical stability, and Zeta potential. Table 3 shows these measurement results of 16 samples which designed according to the orthogonal experiment mentioned above.

The orthogonal tests were subjected to a range analysis based on the data in Table 3, which allowed visualizing the primary and secondary factors and the optimal combination as calculated $R_{i}$ value from equation (1). The results of analysis are shown in Table 4:

$$
R_{i}=k_{i m}(\max )-k_{i m}(\min ),
$$

where $k_{i m}$ is the average of the test results corresponding to the level of the factor $m$ in column $i$ and $R_{i}$ is the range of factor $i$, which reflects the change in the test index when the level of factor $i$ changed. A larger $R_{i}$ indicated a greater impact of the factor on the test index. Therefore, the primary and secondary relationships of the factors based on $R_{i}$ can be determined.

The range analysis in Table 4 shows that the influence of several factors based on the $R_{i}$ value for the viscosity, mechanical stability, and Zeta potential of SBS latex is as follows: water/SBS mass ratio $>$ emulsifier content $>$ inorganic stabilizer content $>$ organic stabilizer content, water/SBS mass ratio $>$ emulsifier content $>$ organic stabilizer content $>$ inorganic stabilizer content, and water/SBS mass ratio $>$ emulsifier content $>$ organic stabilizer content $>$ inorganic stabilizer content, respectively. Thus, water/ SBS mass ratio is the primary factor, and emulsifier content is the secondary factor for all the three technical indexes. However, the influence of both the stabilizers content on the technical indexes is far less than water/SBS mass ratio and 

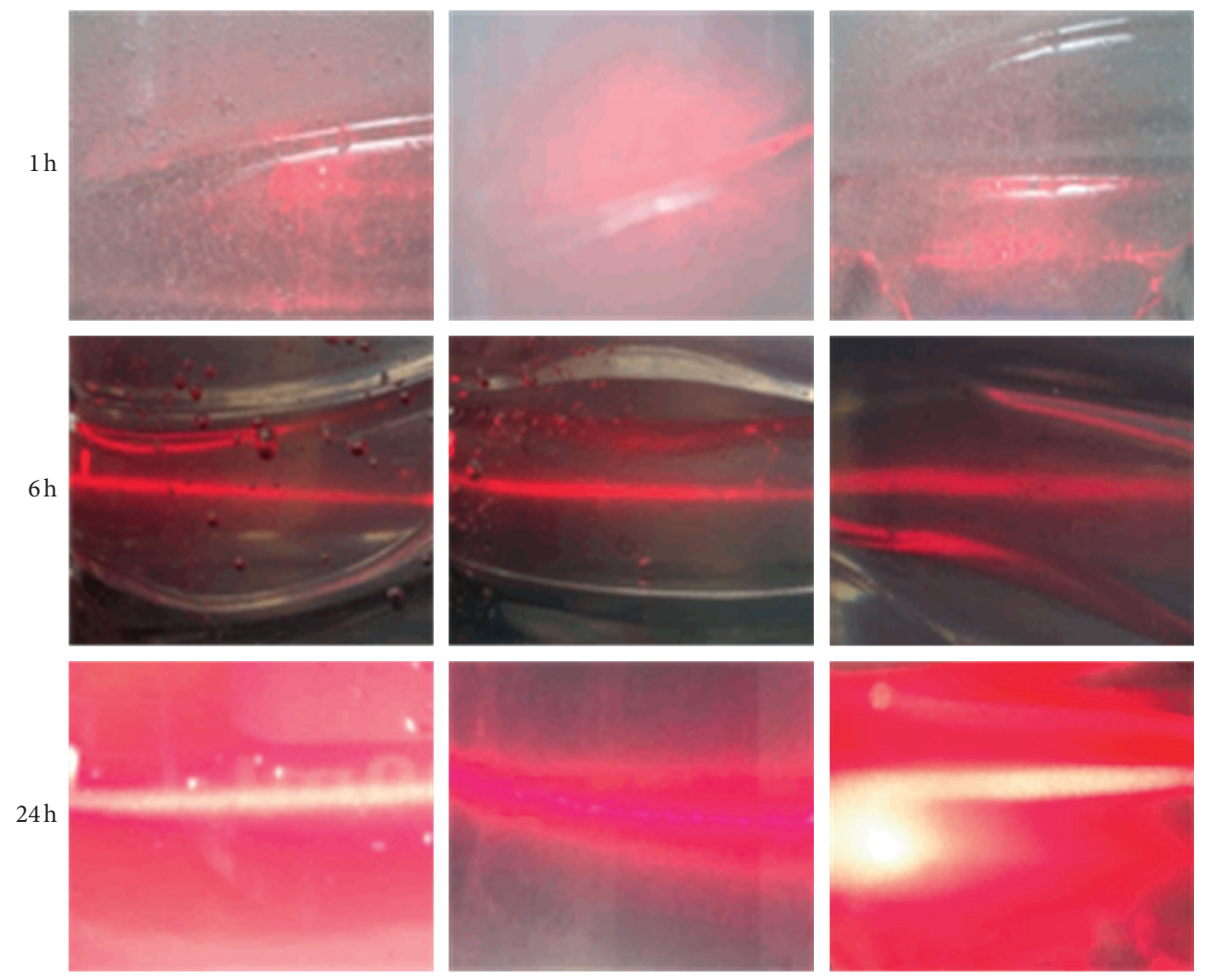

FIGURE 6: The appearance of SBS solution in the presence of a red laser light passageway.

TABLE 2: Factors and levels of orthogonal experimental design.

\begin{tabular}{|c|c|c|c|c|}
\hline \multirow{2}{*}{ Levels } & \multicolumn{4}{|c|}{ Factors (the dosage of each material is based on the mass of SBS) } \\
\hline & Water/SBS (mass ratio) (A) & Emulsifier/\% (B) & Inorganic stabilizer/\% (C) & Organic stabilizer/\% (D) \\
\hline 1 & 0.6 & 8 & 0.1 & 0.1 \\
\hline 2 & 0.8 & 10 & 0.2 & 0.2 \\
\hline 3 & 1.0 & 12 & 0.3 & 0.3 \\
\hline 4 & 1.2 & 15 & 0.4 & 0.4 \\
\hline
\end{tabular}

TABLE 3: Parameters and result of the orthogonal experiments for SBS latex.

\begin{tabular}{|c|c|c|c|c|c|c|c|}
\hline \multirow{2}{*}{ Sample no. } & \multicolumn{4}{|c|}{ Factors } & \multicolumn{3}{|c|}{ Measurement results $\left(25^{\circ} \mathrm{C}\right)$} \\
\hline & A & $\mathrm{B}$ & $\mathrm{C}$ & $\mathrm{D}$ & Viscosity $(\mathrm{mPa} \cdot \mathrm{s})$ & Mechanical stability (\%) & Zeta potential $(\mathrm{mV})$ \\
\hline 1 & 0.6 & 8 & 0.1 & 0.1 & 2473 & 12.8 & 39.5 \\
\hline 2 & 0.6 & 10 & 0.2 & 0.2 & 2756 & 12.1 & 46.8 \\
\hline 3 & 0.6 & 12 & 0.3 & 0.3 & 3569 & 11.9 & 46.1 \\
\hline 4 & 0.6 & 15 & 0.4 & 0.4 & 4359 & 11.9 & 47.3 \\
\hline 5 & 0.8 & 8 & 0.2 & 0.3 & 1472 & 2.3 & 59.1 \\
\hline 6 & 0.8 & 10 & 0.1 & 0.4 & 1689 & 0.8 & 63.5 \\
\hline 7 & 0.8 & 12 & 0.4 & 0.1 & 1780 & 2.0 & 62.3 \\
\hline 8 & 0.8 & 15 & 0.3 & 0.2 & 1874 & 2.2 & 62.7 \\
\hline 9 & 1.0 & 8 & 0.3 & 0.4 & 670 & 6.2 & 52.3 \\
\hline 10 & 1.0 & 10 & 0.4 & 0.3 & 835 & 3.8 & 59.6 \\
\hline 11 & 1.0 & 12 & 0.1 & 0.2 & 923 & 4.0 & 62.1 \\
\hline 12 & 1.0 & 15 & 0.2 & 0.1 & 1023 & 4.0 & 59.8 \\
\hline 13 & 1.2 & 8 & 0.4 & 0.2 & 156 & 9.4 & 40.3 \\
\hline 14 & 1.2 & 10 & 0.3 & 0.1 & 258 & 7.0 & 45.8 \\
\hline 15 & 1.2 & 12 & 0.2 & 0.4 & 340 & 7.2 & 45.2 \\
\hline 16 & 1.2 & 15 & 0.1 & 0.3 & 367 & 8.2 & 39.6 \\
\hline
\end{tabular}


TABLE 4: Range analysis on the viscosity, mechanical stability, and zeta potential of SBS latex.

\begin{tabular}{|c|c|c|c|c|c|}
\hline & Factor & A & $\mathrm{B}$ & $\mathrm{C}$ & $\mathrm{D}$ \\
\hline \multirow{7}{*}{ Viscosity $(\mathrm{mPa} \cdot \mathrm{s})$} & $k_{1}$ & 3289.25 & 1192.75 & 1363.00 & 1383.50 \\
\hline & $k_{2}$ & 1703.75 & 1384.50 & 1427.25 & 1427.25 \\
\hline & $k_{3}$ & 862.75 & 1653.00 & 1592.75 & 1560.75 \\
\hline & $k_{4}$ & 280.25 & 1905.75 & 1782.50 & 1764.50 \\
\hline & $R$ & 3009.00 & 713.00 & 419.5 .00 & 381.00 \\
\hline & Order of factors* & \multicolumn{4}{|c|}{$\mathrm{A}>\mathrm{B}>\mathrm{C}>\mathrm{D}$} \\
\hline & Optimization level & - & - & - & - \\
\hline \multirow{7}{*}{ Mechanical stability \% } & $k_{1}$ & 12.18 & 7.68 & 6.45 & 6.45 \\
\hline & $k_{2}$ & 1.83 & 5.93 & 6.40 & 6.93 \\
\hline & $k_{3}$ & 4.50 & 6.28 & 6.83 & 6.55 \\
\hline & $k_{4}$ & 7.95 & 6.58 & 6.78 & 6.53 \\
\hline & $R$ & 10.35 & 1.75 & 0.43 & 0.48 \\
\hline & Order of factors & \multicolumn{4}{|c|}{$\mathrm{A}>\mathrm{B}>\mathrm{D}>\mathrm{C}$} \\
\hline & Optimization level & A2 & B2 & $\mathrm{C} 2$ & D1 \\
\hline \multirow{7}{*}{ Zeta potential $\mathrm{mV}$} & $k_{1}$ & 44.93 & 47.80 & 51.18 & 51.85 \\
\hline & $k_{2}$ & 61.90 & 53.93 & 52.73 & 52.98 \\
\hline & $k_{3}$ & 58.45 & 53.93 & 51.73 & 51.10 \\
\hline & $k_{4}$ & 42.73 & 52.35 & 52.38 & 52.08 \\
\hline & $R$ & 19.17 & 6.13 & 1.55 & 1.88 \\
\hline & Order of factors & \multicolumn{4}{|c|}{$\mathrm{A}>\mathrm{B}>\mathrm{D}>\mathrm{C}$} \\
\hline & Optimization level & $\mathrm{A} 2$ & $\mathrm{~B} 2$ & $\mathrm{C} 2$ & $\mathrm{D} 2$ \\
\hline
\end{tabular}

${ }^{*}$ There is no specific requirement for viscosity (no influence on AE preparation at later stage), so the optimization level is not proposed.

emulsifier content. From the above analysis in Table 4 and meanwhile the economic factor was considered, the optimal combinations were obtained: water/SBS mass ratio $(0.8)+$ cationic emulsifier (10\%, cationic/nonionic emulsifier mass ratio $3: 1)+$ inorganic stabilizer $(0.2 \%)+$ organic stabilizer $(0.1 \%)$.

3.2.2. Performance of SBS Latex. The performance of SBS latex with different T/S ratios is summarized in Table 5. As mentioned previously, SBS content can greatly affect the viscosity of samples. It can be seen from Table 5 that the test values of viscosity and mechanical stability both increase with the increasing SBS content. However, for the results of particle size and Zeta potential, the test values fluctuate around the T/S ratio $2.0: 1$. Although high solid content of SBS is beneficial for the following performance of AE residue, it might cause severe difficulty in the preparation of SBS-LMAE. Usually, a latex with poor mechanical stability, which is higher than $0.5 \%$, will break when stirred by strong vibration or mechanical shear and influence the stability of AE [10]. Overall, the properties of the latex samples which prepared by the T/S ratios of $2.5: 1$ and $2.0: 1$ are suitable.

3.2.3. Performance of Concentrated SBS Latex. For the modification of AE, the performance of concentrated SBS latex is essential, which is presented in Table 6. It can be found that the data in Table 6 almost demonstrate the same rule as those in Table 5. The difference mainly lies in that the test values of solid content, viscosity, particle size, Zeta potential, and mechanical stability in Table 6 which are much greater than those in Table 5. It can be explained that toluene plays a lubricating role and promotes the dispersion of the SBS droplets and then declines the viscosity of latex.
TABLE 5: Performance specifications of SBS latex.

\begin{tabular}{lccc}
\hline Technical index & T/S ratio 2.5: & T/S ratio 2.0: & T/S ratio 1.5: \\
& 1 & 1 & 1 \\
\hline Ionic charge & Cation & Cation & Cation \\
$\mathrm{pH}$ & $6-7$ & $6-7$ & $6-7$ \\
Solid content $/ \%$ & 23.67 & 28.83 & 29.54 \\
Viscosity $(\mathrm{mPa} \cdot \mathrm{s})$ & 1107 & 1536 & 1967 \\
Particle size $\mu \mathrm{m}$ & 2.44 & 1.68 & 1.96 \\
Zeta potential mV & 51.6 & 52.8 & 48.2 \\
Mechanical stability & 0.28 & 0.35 & 0.73 \\
$\%$ & & & \\
\hline
\end{tabular}

TABle 6: Performance specifications of concentrated SBS latex.

\begin{tabular}{lccc}
\hline Technical index & T/S ratio 2.5: & T/S ratio 2.0: & T/S ratio 1.5: \\
& 1 & 1 & 1 \\
\hline Ionic charge & Cation & Cation & Cation \\
pH & $6-7$ & $6-7$ & $6-7$ \\
Solid content $\%$ & 33.93 & 41.38 & 40.17 \\
Viscosity $(\mathrm{mPa} \cdot \mathrm{s})$ & 1731 & 3820 & 4316 \\
Particle size $\mu \mathrm{m}$ & 2.86 & 2.23 & 2.47 \\
Zeta potential mV & 55.1 & 59.4 & 51.3 \\
Mechanical stability & 0.32 & 0.48 & 1.13 \\
$\%$ & & & \\
\hline
\end{tabular}

Therefore, when the toluene is distilled, the viscosity increases sharply. Meanwhile, most of the gaps between dispersed phases dismiss after the concentration, causing the clusters of SBS droplets evolve to agglomerations. So, the particle size increases, and the mechanical stability becomes worse to some extent.

Nevertheless, the average droplet size range of $2-3 \mu \mathrm{m}$ can still match the particle size distribution of most $\mathrm{AE}$ 
products, $2-10 \mu \mathrm{m}$ [22]. It means that the concentrated SBS latex still has the potential compatibility with $\mathrm{AE}$ and the good penetrative ability in aggregate or structure surface. Furtherly, the Zeta potential, which is an important indicator about the structure stability of single droplet, is even greater than that before concentration. It demonstrates the large repulsive forces between the individual droplets and good stability of the distilled latex. From the analysis above, the fabricated SBS latex is qualified to be used for preparing SBS-LMAE.

3.2.4. Morphology Analysis of SBS Latex and Concentrated SBS Latex. Figures 7 and 8 present the corresponding fluorescence micrographs of SBS latex and concentrated SBS latex samples. As depicted in Figure 7, the swollen SBS polymer is sheared into small spheres and dispersed in solvent uniformly. The oil-in-water structure is formed, and no obvious aggregation and gelation phenomenon can be observed in the figures. Also, there is a distinct boundary between spheres and solvent, indicating a favorable dispersion and stability. It is noteworthy that compared with Figures $7(\mathrm{a})$ and $7(\mathrm{~b})$, the distance between the spheres in Figure $7(c)$ is greatly reduced due to the declined content of toluene.

However, for Figure 8, the boundary between spheres and solvent is smeared severely and the sphere size of SBS is reduced by a big margin, which is attributed to the distillation of toluene. The dispersion state of the droplets looks like being squeezed together rather than uniformly dispersed. With the continuous decreasing of toluene content, the spheres tend to coalesce and obvious droplet flocculation appears in contrast with the individual disperse system in Figure 7, especially in Figure 8(c). It is even difficult to distinguish the morphology of the droplets in Figure 8(c). These phenomena are in consistent with the discussion in Section 3.2.3 and reveal the relatively worse stability. In other words, distillation and concentration process is unfavorable for the dispersion and stability of SBS droplets. In spite of this, with all the results in consideration, the stability of the former two groups is acceptable.

\subsection{Performance Assessment of SBS-LMAE}

3.3.1. Conventional Performance of SBS-LMAE. In the subsequent study, the fabricated SBS latex with the T/S ratio of 2.0:1 was adopted to prepare SBS-LMAE samples with different concentration of SBS. The oil-water ratio used here is $60: 40$. In addition, the content of emulsifier CSFE, inorganic stabilizer, and organic stabilizer is $2.0 \%, 0.3 \%$, and $0.3 \%$ (by the mass of asphalt), respectively. It should be noted that the dosage of SBS latex was calculated according to the concentration of SBS in SBS-LMAE samples. The conventional characteristics of the SBS-LMAEs with different concentration of SBS are listed in Table 7.

The results in Table 7 reveal that the performances of SBS-LMAE samples all meet the main requirements of PMAE for microsurfacing mixtures. For a long time, the drawback of storage stability has been a tough problem for traditional SBS-PMAE. It is quite evident that the test values of storage stability in Table 7 are much smaller than the limitation even when the content of SBS is higher than 4.5\%, which is very important for the transportation and storage of PMAE in the practical application.

As for the conventional characteristics of residue asphalt, the addition of SBS leads to distinct improvement. Generally, with the increasing SBS content, the penetration of evaporation residue declines evidently while the ductility and softening point exhibit similar variation tendency of growth. It can be concluded that the addition of SBS latex causes favorable influence both to the rutting and crack resistance of evaporation residue. This is attributed to the swelling of SBS mixed with residue asphalt leading to improvement in viscosity and elastic recovery. Since the SBS polymer was sheared twice during the preparation procedure of SBS-LMAE, SBS was cut to a dimension of a few micrometers at most, which increase the specific surface area as well as dispersion of the SBS modifier. So, swelling and plasticizing effects of the SBS modifier change the colloidal structure after absorbing the small molecules in asphalt, forming a three-dimensional network of SBS in the evaporation residue. The cross-linked elastomer network not only limits the movement of asphalt but also imparts the strength to the binder. Consequently, the high- and lowtemperature performances of residue asphalt are both greatly improved. It is reported that the stability of the structure of PS core micelles with swollen PB domains as a corona will be influenced when the SBS content exceeds 5\% $[24,25]$. Therefore, the improvement range of each index is obviously reduced as the SBS content comes to $6 \%$.

3.3.2. Morphology Analysis of SBS-LMAE. In this research, the dispersion state and resulting microstructure of the SBS droplets in the emulsion are also characterized using a fluorescence microscope, as shown in Figure 9. As seen in Figure 9(a), the fluorescent image is completely one phase for the unmodified AE, whereas these of Figures 9(b)-9(e) show some light spots. According to former research studies [26], the light spots are due to the fluorescence of the swelling SBS by absorbing light components. It manifests that these light spots in SBS-LMAE are caused by the incorporation of the SBS droplets which converts the morphology from one phase to a biphase structure.

Comparatively, the amount of SBS droplets grows greatly with the increase content of SBS in the emulsion. It is worth to be noted that the size of SBS droplets also increases along with the SBS content, which might be caused by the flocculation of the droplets. Nevertheless, the size change is slight and the polymer is distributed evenly in the emulsion. In addition, the size of the light spots in Figure 9(e) is still smaller than that of the dark spots which represents the asphalt droplets. Furthermore, almost all the dispersed light spots are in the shape of spherical particles, which is beneficial to both the workability and the storage stability of PMAE. All the discussion above reveals that the prepared SBS-LMAE possesses good compatibility between asphalt 


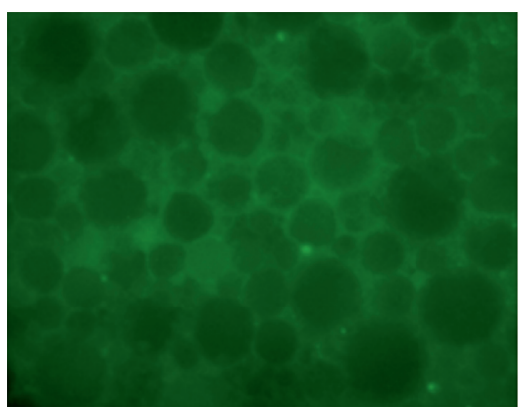

(a)

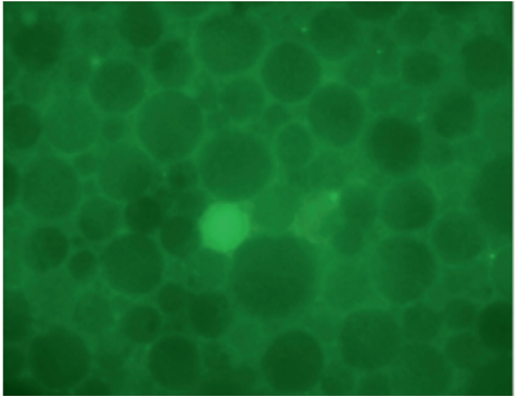

(b)

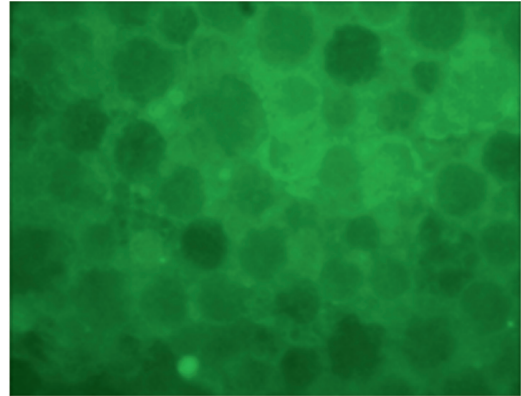

(c)

FIgURe 7: Microstructure of SBS latex with different T/S ratios: (a) 2.5:1, (b) 2.0:1, and (c) 1.5:1 (magnification: $\times 400$ ).

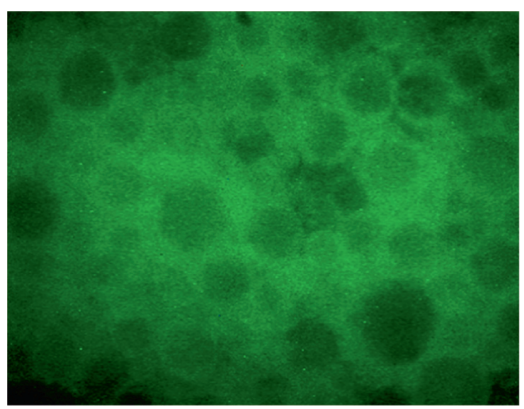

(a)

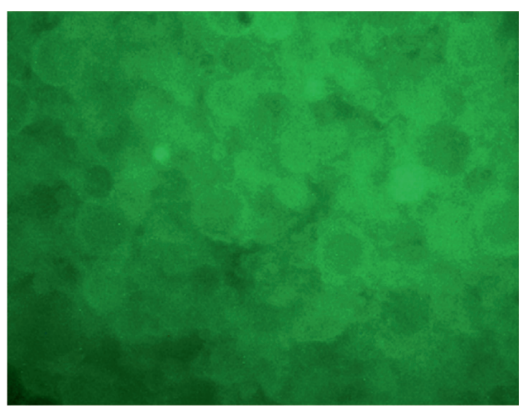

(b)

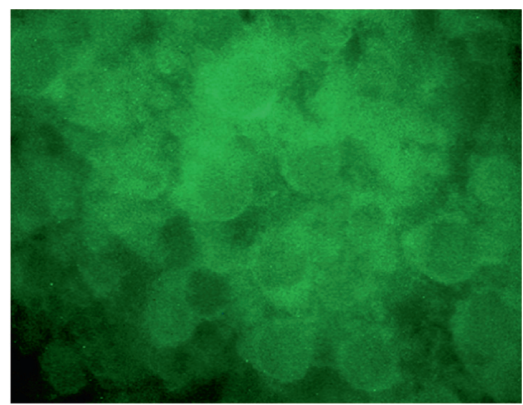

(c)

Figure 8: Microstructure of concentrated SBS latex with different T/S ratios: (a) $2.5: 1$, (b) $2.0: 1$, and (c) $1.5: 1$ (magnification: $\times 400$ ).

TABle 7: Conventional properties of the various SBS-LMAE.

\begin{tabular}{|c|c|c|c|c|c|c|c|}
\hline & \multirow{2}{*}{ Technical index } & \multicolumn{5}{|c|}{ Concentration of SBS \% } & \multirow{2}{*}{ Requirement [23] } \\
\hline & & 0 & 1.5 & 3.0 & 4.5 & 6.0 & \\
\hline \multirow{5}{*}{ Evaporation residue } & Residue content \% & 60.8 & 61.7 & 62.5 & 63.1 & 63.4 & $\geq 60$ \\
\hline & Storage stability (5d) \% & 1.25 & 1.53 & 1.85 & 1.97 & 2.13 & $\leq 5$ \\
\hline & Penetration $\left(25^{\circ} \mathrm{C}\right) / 0.1 \mathrm{~mm}$ & 89 & 85 & 74 & 66 & 62 & $40-100$ \\
\hline & Ductility $\left(5^{\circ} \mathrm{C}\right) / \mathrm{cm}$ & 17.8 & 23.7 & 30.4 & 38.3 & 42.1 & $\geq 20$ \\
\hline & Softening point ${ }^{\circ} \mathrm{C}$ & 46.5 & 54.8 & 63.9 & 76.2 & 77.4 & $\geq 53$ \\
\hline
\end{tabular}

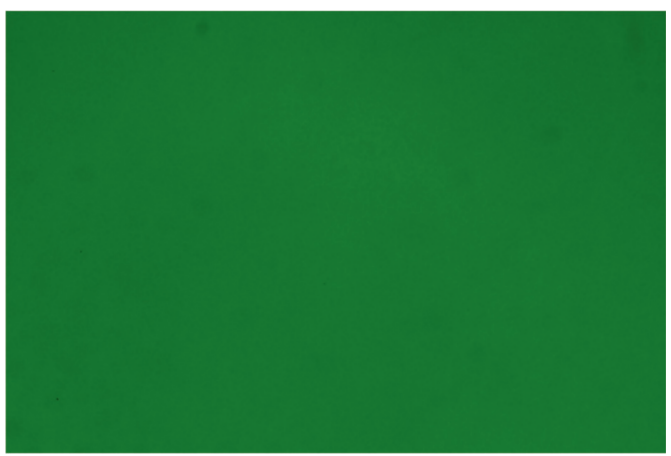

(a)

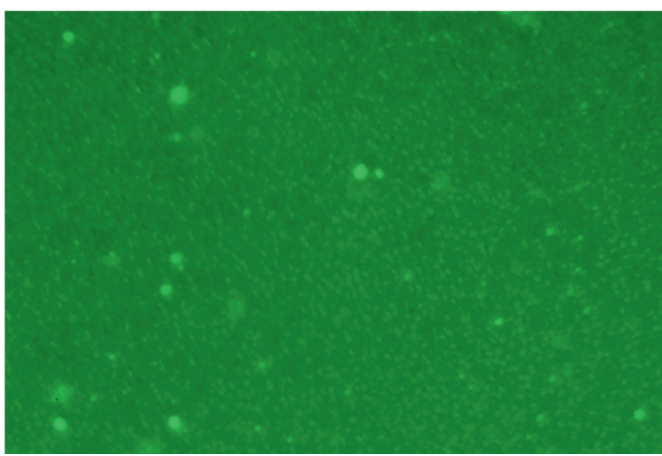

(b)

FIGURE 9: Continued. 


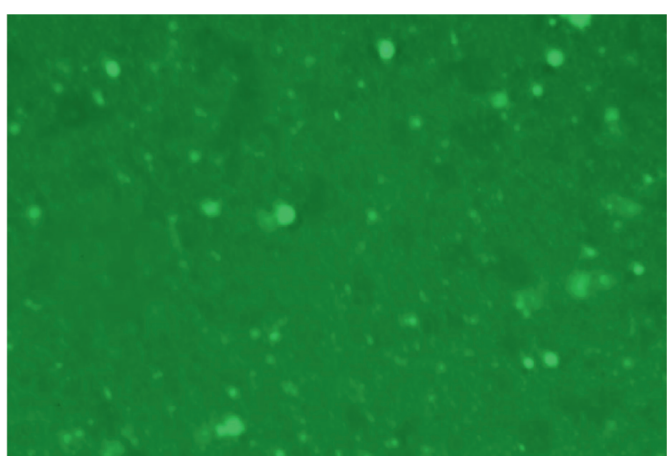

(c)

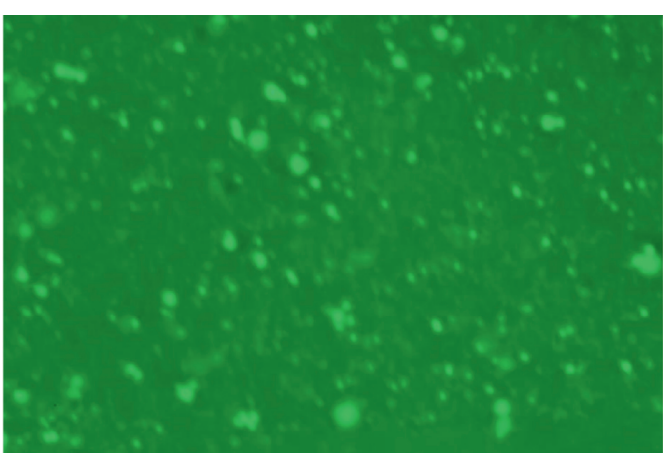

(d)

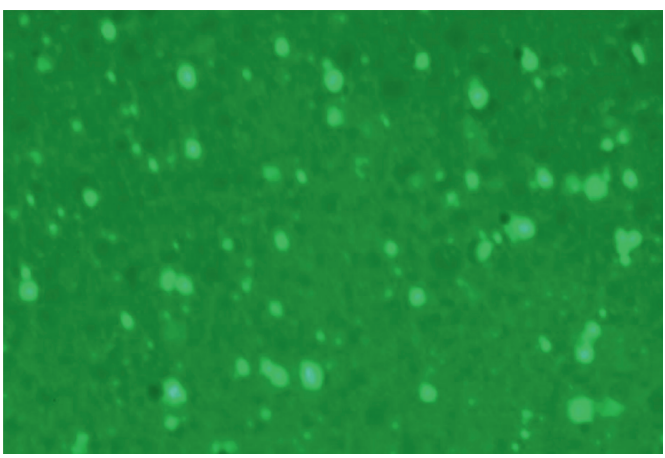

(e)

FiguRE 9: Fluorescence micrographs of SBS-LMAE samples with different SBS concentrations: (a) 0\%, (b) 1.5\%, (c) 3.0\%, (d) 4.5\%, and (e) 6.0\% (magnification: $\times 400$ ).

and SBS droplets and favorable stability as shown in Table 7. Therefore, after the evaporation of the aqueous phase in the emulsion, the latex droplets will coalesce to form a continuous polymer film surrounding the asphalt, especially when the SBS content is $4.5 \%$ or $6.0 \%$. This should lead to improved binder properties, particularly the viscosity of residue asphalt.

\section{Conclusions}

(1) The swelling of linear SBS was fulfilled with the adoption of toluene as solvent. Based on the comprehensive analysis of viscosity and Tyndall effect, the optimized swelling parameters for SBS solutions are determined as swelling $24 \mathrm{~h}$ at the temperature of $50^{\circ} \mathrm{C}$ with the T/S ratios of $2.5: 1$ to $2.0: 1$.

(2) Distillation and concentration process is unfavorable for the dispersion and stability of SBS droplets but beneficial for the solid content enhancement of SBS latex. The fabricated SBS latex with the T/S ratios of $2.0: 1$ possesses the best performance and is qualified to be used for preparing SBS-LMAE.

(3) The conventional performances of SBS-LMAE samples incorporating SBS at the content of $1.5 \%-$ $6.0 \%$ all meet the main requirements of PMAE for microsurfacing mixtures. Addition of SBS latex results in the great improvement of binder performance for residue asphalt, including ductility, softening point, and penetration.

(4) The fluorescence microscope tests reveal that although the increasing content of SBS might cause the flocculation of SBS droplets in the emulsion, the prepared SBS-LMAE possesses good compatibility between asphalt and SBS droplets and favorable stability.

\section{Data Availability}

The data used to support the findings of this study are available from the corresponding author upon request.

\section{Conflicts of Interest}

The authors declare that they have no conflicts of interest.

\section{Acknowledgments}

This study was supported by the Science and Technology Plan Projects in Guangxi Province (no. AC16380112), China Postdoctoral Science Foundation (no. 2019M663602), Key Research Project of Guangxi Province (no. AA18242032), Basic Research Project of Natural Science in Shaanxi Province (nos. 2019JQ-559 and 2019JQ-380), Science and Technology Project of Shanxi Transportation Holdings Group Co., LTD. (no. 18-JKKJ-16), and Transportation 
Science and Technology Projects in Shaanxi Province (no. 19-21K).

\section{References}

[1] K. Chelelgo, Z. C. A. Gariy, and S. M. Shitote, "Modeling of fatigue-strength development in cold-emulsion asphalt mixtures using maturity method," Applied Sciences, vol. 9, no. 13, p. 2694, 2019.

[2] S. Hou, C. Chen, J. Zhang, H. Shen, and F. Gu, "Thermal and mechanical evaluations of asphalt emulsions and mixtures for microsurfacing," Construction and Building Materials, vol. 191, pp. 1221-1229, 2018.

[3] C. Pan, D. Liang, L. Mo, M. Riara, and J. Lin, "Influence of different modifiers on bonding strength and rheological performance of bitumen emulsion," Materials, vol. 12, no. 15, p. $2414,2019$.

[4] A. Khadivar and A. Kavussi, "Rheological characteristics of SBR and NR polymer modified bitumen emulsions at average pavement temperatures," Construction and Building Materials, vol. 47, pp. 1099-1105, 2013.

[5] R. He, S. Zheng, H. Chen, and D. Kuang, "Investigation of the physical and rheological properties of Trinidad lake asphalt modified bitumen," Construction and Building Materials, vol. 203, pp. 734-739, 2019.

[6] A. M. M. Abd El-Rahman, M. El-Shafie, Z. L. Abo-Shanab, and S. A. El-Kholy, "Modifying asphalt emulsion with different types of polymers for surface treatment applications," Petroleum Science and Technology, vol. 35, no. 14, pp. 14731480, 2017.

[7] M. Abedini, A. Hassani, M. R. Kaymanesh, and A. A. Yousefi, "The rheological properties of a bitumen emulsion modified with two types of SBR latex," Petroleum Science and Technology, vol. 34, no. 17-18, pp. 1589-1594, 2016.

[8] F. Zhang and C. Hu, "The research for SBS and SBR compound modified asphalts with polyphosphoric acid and sulfur," Construction and Building Materials, vol. 43, pp. 461-468, 2013.

[9] R. He, S. Wu, X. Wang, Z. Wang, and H. Chen, “Temperature sensitivity characteristics of SBS/CRP-modified bitumen after different aging processes," Materials, vol. 11, no. 11, p. 2136, 2018.

[10] H. M. Cai, T. Wang, J. Y. Zhang, and Y. Z. Zhang, "Preparation of an SBS latex-modified bitumen emulsion and performance assessment," Petroleum Science and Technology, vol. 28 , no. 10 , pp. $987-996,2010$.

[11] M. Abedini, A. Hassani, M. R. Kaymanesh, and A. A. Yousefi, "Low-temperature adhesion performance of polymer-modified Bitumen emulsion in chip seals using different SBR latexes," Petroleum Science and Technology, vol. 35, no. 1, pp. 59-65, 2017.

[12] C. Wang, Y. Wu, K. Xu, and M. Chen, "Styrene-butadiene rubber latex modified bitumen emulsions prepared by phase inversion at low temperature," China Synthetic Rubber Industry, vol. 29, no. 2, pp. 100-103, 2006.

[13] H. Wang, Z. Wang, C. Wang, and Y. She, "Investigation on Storage Stability of SBS modified asphalt emulsion," Acta Petrolei Sinica (Petroleum Processing Section), vol. 29, no. 6, pp. 1009-1014, 2013.

[14] J. K. Lee, K.-R. Lee, and Y. T. Kang, "Development of binary nanoemulsion to apply for diffusion absorption refrigerator as a new refrigerant," Energy, vol. 78, pp. 693-700, 2014.

[15] Z. Shan, Y. Tan, L. Qin et al., "Formulation and evaluation of novel reverse microemulsions containing salmon calcitonin in hydrofluoroalkane propellants," International Journal of Pharmaceutics, vol. 466, no. 1-2, pp. 390-399, 2014.

[16] M. Shafii, J. Ahmad, and E. Shaffie, "Physical properties of asphalt emulsion modified with natural rubber latex," World Journal of Engineering, vol. 10, no. 2, pp. 159-164, 2013.

[17] Standards Press of China, Testing Methods for Synthetic Resin Emulsions, GB/T 11175-2002, Standards Press of China, Beijing, China, 2002.

[18] Chemical Industry Press, Synthetic Rubber Latex-Determination of Viscosity, SH/T 1152-2014, Chemical Industry Press, Beijing, China, 2014.

[19] Chemical Industry Press, Synthetic Rubber Latex-Determination of Total Solids Content, SH/T 1154-2011, Chemical Industry Press, Beijing, China, 2011.

[20] China Communications Press, JTG E20-2011, Standard Test Methods of Bitumen and Bituminous Mixtures for Highway Engineering, China Communications Press, Beijing, China, 2011.

[21] T. Li, Preparation of SBS Latex and its Applications in Microsurfacing Mixtures, Ph.D. thesis, Chang'an University, Xi'an, China, 2016.

[22] J. Ouyang, Y. Sun, and S. Zarei, "Fabrication of solvent-free asphalt emulsion prime with high penetrative ability," Construction and Building Materials, vol. 230, Article ID 117020, 2020.

[23] China Communications Press, JTG 5142-2019, Technical Specifications for Maintenance of Highway Asphalt Pavement, China Communications Press, Beijing, China, 2019.

[24] A. Adedeji, T. Grünfelder, F. S. Bates, C. W. Macosko, M. Stroup-Gardiner, and D. E. Newcomb, "Asphalt modified by SBS triblock copolymer: structures and properties," Polymer Engineering \& Science, vol. 36, no. 12, pp. 1707-1723, 1996.

[25] L. Shan, R. Xie, N. J. Wagner, H. He, and Y. Liu, "Microstructure of neat and SBS modified asphalt binder by smallangle neutron scattering," Fuel, vol. 253, pp. 1589-1596, 2019.

[26] C. Zhu, H. Zhang, D. Zhang, and Z. Chen, "Influence of base asphalt and SBS modifier on the weathering aging behaviors of SBS modified asphalt," Journal of Materials in Civil Engineering, vol. 30, no. 3, 2018. 